\title{
Pariwisata Ubud dalam Teologi Hindu (Manawa Dharma Sastra)
}

\section{Wayan Miartha \\ Program Studi Penerangan Agama Hindu Fakultas Dharma Duta IHDN Denpasar}

\begin{abstract}
Ubud is one of the destinations of a worldwide tourist destination, Ubud which originally was an agrarian traditional village turned into a tourism village, even the village of Ubud has been transformed into a world tourism destination is evidenced by the many awards obtained in the field of tourism. Ubud tourism practitioners have been able to meet the standard of facilities that become the standard needs of tourists themselves, both nationally and internationally, such as the availability of accommodation, restaurant, telecommunications, transportation, entertainment, museums, art gallery and other supporting objects close to Ubud such as Bedahulu, Pejeng, Tampaksiring etc. Ubud tourism is not the same as other tourist destinations in Bali such as Nusa Dua, Sanur, Kuta and others, because Ubud people have different characteristics and lifestyles, the management of Ubud tourism through the concept of Tri Hita Karana combined with Hindu Theology so that existence Ubud tourism can be maintained. In Veda (Manava Dharma Sastra) states that how to serve Tourists such as serving the God (Atithi Deva Bhavo) so that guests will feel at home to visit and settle in Ubud.
\end{abstract}

\section{Keywords: Tourism, Hindu Theology}

\section{Pendahuluan}

Pariwisata dalam era global ini memberikan kontribusi yang sangat besar dalam penerimaan devisa negara, sehingga pada saat ini hampir semua negara-negara yang ada di dunia berlomba-lomba untuk mempromosikan obyek-obyek wisata mereka dalam berbagai bentuk promosi yang tujuannya untuk membentuk image sehingga para wisatawan akan tertarik untuk datang atau berkunjung ke negara-negara tersebut; seperti Malaysia dengan slogannya Malaysia Truly Asia dengan menampilkan alam tropisnya beserta dengan faunanya begitu pula budaya Malayunya. India dengan mottonya Increadible India menampilkan bangunan cagar budaya yang sangat indah, alam pegunungan dan faunanya yang menakjubkan, tarian beserta busana sharinya dan perjalanan suci Tirtha yatra yang menjadi icon pariwisata India. Thailand menampilkan keindahan pantainya, keramah tamahan masyarakatnya dan budaya kulinernya, juga negaranegara di belahan dunia lainnya tidak kalah giatnya untuk mempromosikan obyek-obyek wisatanya, walaupun mereka sudah termasuk Negara sangat maju seperti Australia, Amerika, Jepang, Hongkong dan negara-negara Eropah masih tetap giat melakukan promosi pariwisatanya.

Seperti apa yang menjadi tujuan parawisata itu sendiri yaitu; untuk bisa memenuhi keinginan wisatawan sesuai dengan motivasi dan kegiatan wisata yang mereka akan lakukan di negara yang menjadi tujuan mereka, tapi tak kalah pentingnya sesuai dengan tujuan utama pariwisata itu adalah memberikan "kemakmuran materi" kepada daerah atau negara yang dituju. Sedangkan Indonesia dengan ribuan pulau yang terbentang dari Sabang sampai Merauke dengan segala kilauan keindahannya, pantai, flora dan faunanya, budaya dan tradisi serta ketrampilannya, ratusan bahasanya bagaikan gugusan ratna mutu manikam yang tidak ada duanya di jagad ini. Indonesia dalam mempromosikan obyek-obyek pariwisatanya dengan menampilkan beberapa acara festival-festival budaya di pusat maupun di daerah-daerah yang bertaraf nasional maupun Internasional dalam program Visit Indonesia Year adalah untuk menarik minat wisatawan domestik maupun internasional untuk mengadakan perjalanan wisata.

Sejatinya Pariwisata pada awalnya adalah tentang "manusia dan tempat". Di tempat itu dimana mereka tinggal dan hidup berkelompok, dikunjungi atau hanya sekedar berlalu lalang dari kelompok-kelompok manusia lain. Dalam perjalanan waktu lama dunia pariwisata ini berkembang dan kemudian bisa dikatagorikan menjadi perjalanan manusia di dalam dua (2) bentuk yaitu;

Perjalanan luar (outer journey) adalah perjalanan di dalam alam ini (geographical space) yang mempunyai tujuan utama untuk mendapatkan kesenangan fisik (pleasure) dan memenuhi rasa ingin tahu (curiosity). Sehingga pada saat ini banyak sekali bentuk atau paket wisata yang dijual oleh travel agent dari negara yang berbeda untuk bisa menarik wisatawan untuk berkunjung ke negaranya atau kedaerahnya. Seperti apa yang dislogankan oleh Malaysia, India, Thailand, Amerika dengan Dyniesland, Jepang, Eropah dan Australia, maupun negara lainnya yang menginginkan devisa dari industri yang tidak berasap ini. Bahkan pada zaman ini dengan 
kemajuan teknologi manusia bisa bepergian ke ruang angkasa tentunya dengan biaya diluar jangkauan manusia biasa.

Perjalanan Batin (inner journey) adalah manifestasi dari bentuk perjalanan bagian luar dari alam ini (exterior space), yang sudah lama dilakukan oleh kelompok-kelompok manusia, bahkan sudah mentradisi dalam kehidupan religius mereka, yang sudah biasa dilakukan baik secara immanent maupun transedental dan kedua hal ini secara bersama-sama membentuk spiritualitas dan phenomena perjalanan yang complex. Seperti tradisi yang dilakukan oleh orang Hindu di India dengan melakukan Thirta Yatra dari ribuan tahun yang lalu sampai sekarang ke sungai suci dan mengunjungi tempat-tempat suci adalah menjadi kewajiban (doktrin agama) yang harus dilakukan, dengan mandi di air yang suci adalah suatu bentuk ritual yang tujuannya menyuciankan diri lahir bhatin dan mengunjungi tempat-tempat suci yang bertebaran di India adalah usaha orang Hindu untuk mengenali lebih jauh tentang cosmos yang ada disekitar mereka. Begitu pula yang dilakukan umat Islam berkunjung ke Mekkah dan Medinah serta umat Khatolik ke Vatican untuk penyucian diri lahir bhatin, salah satu tujuan pariwisata adalah Bali (Suardana. 4: 2010).

Pulau Bali sangat kecil, tetapi phisiknya secara geografis sangatlah complex, sebuah pulau yang tercipta sangatlah kontras, ditinjau dari outline pulau ini, yang secara garis besar terdiri dari pegunungan, dataran dan pantai. Didalam pulau kecil ini antara barat dan timur tidak sama, diutara Bali pesisirnya sangat kering dan sebelah barat pegunungannya yang sangat subur.

Dalam sejarah Bali Purba diketemukan artifacts seperti sarkopagus, nekara dari perunggu, perhiasan dari manik-maik, peralatan dari besi, peralatan dari tanah liat dan banyak lagi peninggalan purbakala yang kita bisa lihat di Museum-museum, di Pura-pura, disepanjang sungai, dipegunungan ataupun tempat lain yang ada di Bali. Bali mendapatkan beberapa julukan seperti The last of Paradise, The Morning Of The World, The Island Of The Gods dan banyak lagi julukan yang diberikan oleh para penulis asing maupun domestik. Bahkan Bali berturut-turut sampai tujuh kali mendapatkan penghargaan sebagai The Best Of Island dari majalah Travel Leisure. Salah satunya Ubud yang menjadi destinasi pariwisata.

Dewasa ini Ubud bukanlah desa yang sederhana lagi, yang awalnya adalah sebuah desa tradisional agraris berubah menjadi sebuah desa pariwisata, bahkan desa Ubud telah menjelma menjadi tujuan pariwisata dunia. Tentunya desa kecil yang nan indah ini telah mampu memenuhi standard fasilitas yang menjadi standard kebutuhan wisatawan itu sendiri, baik secara nasional maupun internasional, seperti akomodasi, restaurant, telekomunikasi, perbankkan, transportasi, hiburan atau entertaiment, souvenir/cendramata, museum-museum, gallery seni dan objek-objek pendukung lainnya yang ada dekat dengan Ubud seperti Bedahulu, Pejeng, Tampaksiring dll. Pariwisata Ubud tidaklah sama dengan daerah tujuan pariwisata lainnya yang ada di Bali seperti Nusa Dua, Sanur, Kuta dan lainnya, karena masyarakat Ubud mempunyai karakteristik dan gaya hidup yang beda, namun gerak kehidupan masyarakat Ubud yang berkecimpung

\section{Pembahasan}

Letak Desa Ubud yang strategis, yaitu berada di jantung ibu kota Kecamatan Ubud dan merupakan salah satu Kawasan Wisata yang berada di Kabupaten Gianyar yang jarak tempuhnya kurang dari 30 menit. Dengan Pemerintahan Provinsi jaraknya lebih kurang 24 km dan sekitar 40 km dari Airport Ngurah Rai menuju Desa Ubud.

Penduduk Desa Ubud adalah mayoritas beragama Hindu, walaupun ada yang berkeyakinan berbeda. Tapi sangat kecil jumlahnya yang berdiam di Ubud, mereka adalah expat dan penduduk pendatang dari daerah pulau lain yang menetap di Ubud. Struktur sosial masyarakat Ubud seperti Kasta yaitu Brahmana, Kstria, Waisya dan Sudra masih berjalan dengan normal dan sangat dihormati, masih adanya hubungan historis antara Keluarga Puri dengan masyakat biasa masih erat hubungannya, adanya Banjar Tri Wangsa di Padang Tegal Tegah dan Banjar Para Gusti di Taman Kelod mencerminkan betapa kuatnya ikatan-ikatan sosial tersebut.

Sesuai dengan statistik, jumlah penduduk Desa Ubud tahun 2007 berjumlah 11.110 jiwa, dengan jumlah kepala keluarga sebanyak 2.263 dan tahun 2008 meningkat menjadi 11.183 jiwa dengan jumlah kepala kelurga 2.280 jiwa. Penduduk Desa Ubud berdasarkan jumlah kelamin laki/perempuan gender tahun 2007 terdapat 5.611 orang laki-laki dan 5.544 orang perempuan, sedangkan pada tahun 2008 terdapat 5.639 orang laki-laki dan 5.544 orang perempuan. Tingkat kepadatan penduduk Desa Ubud sudah tergolong sangat padat yaitu 1433 jiwa/km2 dibanding kepadatan penduduk menurut PBB adalah $240 \mathrm{jiwa} / \mathrm{km} 2$. Dari tingkat kepadatan penduduk yang sangat padat ini, sudah seharusnya perlu mendapat perhatian yang serius dari pihak yang terkait, supaya kondisi ini tidak membawa masalah dan dampak yang kurang baik tehadap berkembangan 
masyarakat dikemudian hari, yaitu dalam usaha untuk meningkatkan kesejahteraan masyarakat Desa Ubud.

\section{Pariwisata dalam Sastra Hindu}

Keberadaan agama seharusnya dapat memberikan keyakinan sebagai jalan hidup yang rasional. Jika memang spirit itu pernah ada di sebuah rumah di dalam dunia ini, dan tidak hanya sebagai rumah tahanan atau menjadi pelarian diri dari narapidana, dasar fondasi spiritual harus tertanam dalam-dalam dan harus dipelihara sebagai sesuatu yang sangat berharga. Agama harus dapat mengekspresikan pemikiran yang masuk akal, melalui kegiatan yang berbuah dan berdasarkan kelembagaan sosial yang tepat, seperti yang dijabarkan dalam kutipan ini :

"Religious feeling must establish itself as a rational way of living. If ever the spirit is to be at homein this world, and not merely a prisoner or a fugitive, spiritual foundations must be laid deep and preserved worthily. Religion must express itself in reasonable thought, fruitful action and right social institutions". (Radhakrishnan, webarchive 26-3-2010).

Veda dalam agama Hindu merupakan ibu dari segala ilmu pengetahuan, hampir tidak ada ilmu pengetahuan yang tidak bersumberkan pada ajaran Veda, diantaranya adalah seperti; ilmu pengetahuan astronomi, spiritualitas, filsafat, alam, bhakti, Karma, politik, estetika, ekonomi, struktur sosial dan sistim kemasyarakatan, hukum, musik, tarian, phisik dan banyak lagi ilmu pengetahuan lainnya. Dikatakan dalam Veda apapun yang ada dialam ini ada dalam Veda itu sendiri. Veda adalah kebijaksanaan yang abadi, yang terkandung dalam waktu yang tidak terbatas, dari norma-norma eksistensi yang tercipta. Veda disampaikan melalui manusia super "super human" yang aslinya bersumber pada ekspresi pikiran Tuhan. "(apauruseya).

"the Vedas is eternal wisdom, and contains the timeless rules of all created existence. The Vedas are of super human origin (apauruseya) and express the mind of God." (S. Radhakrishnan, 1999; 495).

Orang-orang Vedanta berujar bahwa Veda diucapkan oleh Isvara dalam setiap era Yuga yang berbeda. Veda adalah kumpulan dari huruf-huruf, kata-kata dan kalimat-kalimat, yang eksis dalam setiap penciptaan dan abadi sifatnya dalam alam semesta ini.

" the vedas contain all the knowledge. Bless me with this knowledge just as you have bless the deiteis. O pioneer Deities! Knowing the path of truth tread on it. Only by acquiring knowledge from vedas can one know the path of truth and rightenousness. Vedas means knowledge and the Vedas an ocean of knowledge".Yajur Veda. (Madhu Varshney, webarchive: 3-3-2010).

Dari petikan paragraf ini dapat di uraikan bahwa bahwa Veda itu adalah samudra dari pengetahuan, yang artinya segala bentuk ilmu pengetahuan bersumber dari Veda dan segala bentuk ilmu pengetahuan itu ada dalam samudra tersebut.

Mengacu atau bertitik tolak dari ungkapan ini, apakah pariwisata itu bersumber dari ajaran Veda itu sendiri. Kalau dilihat secara "tradisional dan sesuai dengan sejarahnya", pariwisata memang di awali dengan suatu perjalanan suci (pilgrimege). Adalah suatu perjalanan manusia secara fisik dalam usahanya untuk mencari suatu kebenaran, mencari kebenaran yang dilandasi dengan nilai-nilai yang sakral atau nilai kesucian. Manusia menenggelamkan diri ditempat yang mereka yakini keramat dan suci, didalam sebuah tempat yang penuh dengan kekuatan Ilahi. Tempat yang keramat sakral dan suci bagaikan magnet yang mampu menarik spiritualitas mereka untuk menemukan kebenaran, pencerahan atau mendapatkan pengalaman yang otentik dari para dewa maupun dari para orang suci. Mengadakan perjalanan ketempat yang sakral lazimnya berbeda ritualnya dengan tempat yang profan, ritualnya tidak seperti kebiasaan setiap hari.

Perkataan Satya (kebenaran) berasal dari kata "Sat" yang artinya "Ada," dan pada hakekatnya tak ada sesuatu selain dari pada kebenaran. Sebab itu Sat atau kebenaran adalah nama yang terpenting untuk Tuhan. Dan sebenarnya menurut Gandhi lebih tepat untuk mengatakan bahwa "Kebenaran adalah Tuhan daripada Tuhan adalah Kebenaran" (D.S. Sarma,1951;16). Tetapi nama-nama yang lain masih tetap dipergunakan juga seperti Yang Maha Kuasa, Seru Sekalian Alam dll, karena tidak mungkin manusia hidup tanpa pemimpin. Tetapi jika manusia berfikir lebih dalam lagi mereka akan insaf bahwa "Sat" satu-satunya nama yang tepat. Yaitu dimana ada kebenaran disitupun akan ada pengetahuan yang sejati, sebab itu nama "Chit" atau pengetahuan adalah bertalian dengan nama Tuhan. Dalam hal ini dimana ada "pengetahuan" yang sejati disitu juga akan ada "kesejahteraan dan kebahagian" (ananda) serta disitu juga tidak akan ada tempat kesengsaraan bagi umat nanusia. Sebagai "Kebenaran" akan kekal dan abadi demikian 
juga dengan "Kesejahteraan" adalah kekal, itulah sebabnya Tuhan kita kenal sebagai "Sat Chit Ananda" adalah suatu kesatuan yang mempersatukan didalam diriNya yaitu; kebenaran, pengetahuan dan kesejahteraan.

Gandhi lebih jauh mengatakan (D.S. Sarma, 1951:18) bahwa; jika mungkin Tuhan itu dapat dilukiskan dalam bahasa manusia maka kesimpulannya Tuhan itu adalah Kebenaran. Biarpun or ang tidak mengakui keberadaan Tuhan, tetapi dia sendiri akan mengakui keharusan akan adanya suatu Kebenaran. Tetapi dalam keinginannya mengejar Kebenaran mereka ini dengan tidak ragu-ragu memungkiri adanya Tuhan jika dilihat dari sudutnya mereka tak ada salahnya. Dengan mengingat hal ini, insaflah Gandhi bahwa lebih baik untuk mengatakan bahwa Kebenaran adalah Tuhan daripada bahwa Tuhan adalah Kebenaran. Jika manusia menemukan "Kebenaran" berarti manusia tersebut telah menemukan "jati dirinya."

Agama memotivasi perjalanan manusia, termasuk orang yang melakukan perjalanan suci, perjalanan ini mengalami pertumbuhan sangat pesat sekali dalam pertengahan abad ke 20an. Memang sangat mengejutkan sekali perkembangan perjalanan suci ini yang begitu pesatnya, tetapi disatu sisi perkembangan perjalanan suci keagamaan tersebut juga mengalami masa-masa yang krisis, yaitu kehilangan sosial kelembagaannya secara significant. Akibat dengan adanya perjalanan suci keagamaan yang berbau modern. Perjalanan suci modern ini menampakkan keganjilan yang mencolok, berbeda dari kebiasaan-kebiasaan dan kepercayaan yang telah dilakukan selama berabad-abad oleh masyarakat setempat. Apakah akibat dari pengaruh pembangunan yang berdasarkan imtek yang sangat progresif di negara-negara Barat, sehingga mereka memiliki peradaban modern dengan kehidupan dan sistim sosial mereka yang begitu komplek.

Dalam kehidupan modern ilmu pengetahuan dan teknologi memiliki peran penting dan strategis, mungkin mereka menganggap lebih beralasan melakukan kegiatan spiritualitas yang lebih di sederhanakan. Karena akan dianggap lebih efesien dan lebih efektif dari pada melaksanakan ritual-ritual yang berdasarkan magic, kepercayaan dan agama yang mereka anggap tidak rasional untuk dilakukan lagi.

Di dalam budaya postmodern, agama dianggap sangat pribadi/private, orang yang mempunyai kemampuan bisa mengkemas suatu perjalanan suci melalui cyber yaitu melalui situs Website. Seharusnya kegiatan ini diperdebatkan! Karena dengan kemajuan internet orang bisa mengakses apapun yang mereka inginkan seperti pornografi, geografi bahkan masalah yang sangat pribadi dalam kehidupan manusia pun bisa diakses dll. Orang mengakses internet yang sifatnya sangat pribadi (privacy), jadi orang lain tidak tahu apa yang mereka cari dan seharusnya mereka memang tidak perlu tahu, apa orang lain inginkan. Dalam internet dewasa ini apapun bisa didapat, akan menjadi sebuah atraksi yang sangat menyita perhatian bagi siapapun pula. Begitu hebatnya perkembangan teknologi, akan bisa menimbulkan masalah bagi seorang penekun spiritual apabila mereka terpengaruh oleh atraksi-atraksi tersebut, apakah mereka tidak akan pernah mengakses website pornografi. Karena orang berbelanja lewat internet akan selalu bersentuhan langsung dengan website, walaupun dijamin berbelanja melalui internet relatif aman. Dewasa ini dengan adanya komunitas cyberspace, dimana orang akan memasuki dunia yang digambarkan sebagai sebuah tempat "place" yang biasanya orang pergi ketika mereka on line, mereka memakai perangkat computer dan internet untuk berhubungan dengan orang lain. Saat itulah dikatakan manusia begerak (moving) didalam suatu ruang dan tempat cyberspace.

" Cyberspace we might want to say is an imaginary place, but anyone who has spent little time in cyberspace knows that what you find there is no imaginary. Cyberspace may not be physical space, but it is very real." (Sthepen K. Spyker, 2007: 57).

Sepertinya orang bertemu didalam cyberspace layaknya mereka bertemu nyata dan langsung, dalam arti kata bertemu dengan kejadian di sebuah tempat nyata (physical space). Seharusnya manusia mempunyai peran utama berpatisipasi secara langsung, adalah sebagai bentuk refleksi dari perjalanan spiritual dimana keotentikan pengalaman tidak tergantung dari orang lain. Dalam hal ini perjalanan spiritual manusia tersebut tidak menjadi bagian dari struktur kelembagaan agama itu. Menurut hasil dari suatu observasi, orang yang melakukan perjalanan suci sangat meningkat pesat jumlahnya dan bahkan animonya tidak pernah berkurang, ini bisa dilihat perkembangan perjalanan suci di benua Eropah. Mereka mengunjung tempat suci (religious sites) sangat meningkat, sementara peziarah ke gereja-gereja mengalami kemunduran (Nolan and Nolan 1992). Secara global kebangkitan kembali perjalanan suci keagamaan telah terjadi, termasuk munculnya fundamentalisme (Frienland 1999). Kemunduran terhadap beberapa kepercayaan agama, mengalih menuju bentuk spiritual yang tradisionil seperti zaman pertengahan (Post at al.1998). Terjadinya pelonjakan investasi dalam sekala yang sangat besar dalam transportasi infrastruktur (Griffin 1994), Begitu pula perkembangan dibidang advertasing dari global sampai 
media local mempromosikan perjalanan ini dengan peningkatan yang tajam. Ini menandakan jumlah kenaikan dari orang untuk mencari jawaban atas pertanyaan tentang existensi manusia dan termasuk tentang apa yang dimaksud dengan hidup itu sendiri.

Sejalan dengan yang dikatakan oleh para sarjana, banyak manusia dari kedua belahan dunia ini, manusia mengalami dislokasi dan kehilangan jati diri, mereka terlalu membenamkan diri didalam kehidupan modern yang materialistis, khususnya di dunia Barat. Kehidupan sosial dalam postmodern; manusia mencari diri mereka sendiri, dalam usahanya untuk mendapatkan kesadaran indera. Menurut Nuryanti (1996:25) dalam abad dua puluhan adalah merupakan fase atau bagian dari pembentukan karakteristik dari suatu gerakan warisan masa lalu, manusia saat ini aktif mencari akar leluhur mereka. Intisarinya mereka mencari suatu pemahaman yang meliputi masa lalu, dengan mempertanyakan suatu petanyaan "Siapakah aku ini." Dalam perjalanan waktu yaitu dalam suatu momen "Siapakah aku sebelumya" melalui pencarian dari tingkatan yang ingin diraih dari orientasi yang baru...... dalam penguatan... perbatasan dan menciptakan suatu hal yang baru (Paasi, 2003 : 475).

Dalam zaman globalisasi ilmu pengetahuan dan teknologi tidak dapat diabaikan oleh manusia dari lapisan, golongan manapun. Sebab ilmu pengetahuan dan teknologi mempunyai peran dan pengaruh yang sangat dominan dalam tatanan kehidupan manusia baik masa sekarang maupun dimasa yang akan datang. Mereka harus kooperative saling mendukung, tidak bisa lepas dan mempunyai ketergantungan satu dengan yang lainnya (intergrated). Dalam tujuannya untuk mencapai kesejahteraan masyarakat dunia, dengan kesetaraan yang harmoni dan seimbang, serta dalam usaha menurunkan angka kemiskinan dan perbudakan.

Seperti halnya dalam dunia pariwisata maju mundurnya pariwisata suatu daerah atau negara sangat dipengaruhi oleh factor-factor internal maupun eksternal seperti kondisi politik yang kurang kondusif, crisis ekonomi, masalah terrorisme, perang dan lain sebagainya. Pariwisata pada zaman global ini mempunyai nilai ekonomis yang sangat tinggi dan menjadi andalan suatu daerah atau negara untuk mendapatkan devisa yang sebesar-besarnya. Dalam era yang serba canggih, akibat dari pengaruh kemajuan teknologi dan ilmu pengetahuan, mobilitas manusia menjadi sangat tinggi.

Dari banyak penemuan-penemuan penting dunia yang menakjubkan seperti di bidang transportasi dan telekomunikasi dapat dipakai untuk memenuhi kebutuhan kepentingan umat manusia. Seperti yang bisa diakses di media masa, bahwa tidak lama lagi manusia akan bisa mengadakan perjalanan wisata ke alam lain, yang artinya manusia tidak hanya melakukan perjalanan wisata di bumi saja, tetapi manusia akan bisa melakukan perjalanan di luar angkasa. Perjalanan wisata manusia tersebut apakah hanya sekedar ingin tahu saja atau sambil mengadakan explorasi untuk kepentingan yang lebih luas dan akan menetukan kehidupan manusia dimasa yang akan datang. Ada suatu pertanyaan timbul, jika manusia dalam explorasinya berahasil menguasi luar angkasa, apakah sengketa-sengketa agama yang mengancam keberlangsungan kehidupan manusia di bumi ini, akan berlanjut nanti diluar bumi tersebut. Dan akankah mereka saling mengklaim bahwa merekalah yang lebih lebih baik atau superior dari yang lainnya. Perang Dingin antar blok Kapitalis dengan Komunisme telah berlalu beberapa dekade lalu dengan tumbangnya aliansi Sovyet. Dengan tumbangnya aliansi blok Timur kemenangangan ada dalam genggeman kapitalisme, Blok Sovyet terpecah-pecah menjadi beberapa negara-negara yang merdeka, seperti negara Rusia, Maldova, Ubekistan, Kajkistan dan lain-lain.

Tetapi dilain pihak dengan kemenangan Kapitalisme, mereka juga tidak merasa nyaman dengan kondisi yang mereka hadapi, adanya ancaman crisis ekonomi ataupun crisis politik akibat dari kesalahan kebijaksanaan secara global. Menjadi momok yang selalu membayangi dan akan menjadi ancaman serius kalau mereka tidak mempersiapkan diri melalui kekuatan militernya. Mereka harus memilki kekutan militer dengan persenjataan canggih yang melebihi kekuatan kekuatan negara-negara lain diidang sumber daya manusia dan persenjataan yang canggih. Adalah usaha-usaha negara-negara blok kapitalis untuk menguasai sumber daya alam untuk kepentingan industrinya. Kadang-kadang negara kapitalis sangat cuek, tanpa menghiraukan atau menghormati keberadaan kebudayaan dan kepercayaan negara lain demi kepentingannya.

Alam diexplorasi secara habis-habisan dan adanya kesan alam harus ditaklukan oleh manusia modern. Mereka sangat matematis sekali dalam hitungan hanya mementingkan material saja dengan mengagung-agungkan materialisme. Tetapi kalau ditinjau dari kepercayaan Hindu, kehidupan yang demikian tidak akan pernah bisa menciptakan suatu kehidupan yang seimbang dan harmonis, yaitu keseimbangan antara dunia materialisme, dunia agama dan dunia spiritual. Dalam dunia modern materialisme adalah segala-galanya dan merupakan tujuan kehidupan yang harus dicapai, dengan asumsi ketika orang sudah memiliki artha yang banyak mereka dinobatkan menjadi raja. Adakalanya seseorang yang dianggap raja yang sudah dilayani dengan sangat baik, tetapi mereka masih merasa belum puas dan juga berperilaku yang tidak-tidak pada si pelayan. Apa tamu atau pembeli itu sendiri bisa dianggap raja, bila mereka mau berbuat semena-mena 
karena mereka memiliki artha. Asumsi tersebut tidak sepenuhnya dapat dibenarkan, dengan alasan jika memang orang tersebut memiliki tabiat yang tidak baik, berpura-pura, diktator atau orang yang mau menang sendiri, tanpa bisa menerima keberadaan orang lain.

Seharusnya seorang tamu atau pembeli memegang moralitas dan spirit saling menghargai. Biasanya didunia pariwisata pernyataan wisatawan yang tidak puas akan memiliki pencitraan yang tidak baik pada daerah, negara yang dikunjungi, biasanya mereka sangat provokatif sekali dengan pelayanan atau penerimaan yang mereka anggap tidak sesuai dengan apa yang mereka harapkan. Daerahnya kotor, fasilitas jelek dan kurang mendukung, polusi, traffik yang tidak teratur dan macet ini dan itu. Biasanya ini akan menjadi bagian propaganda yang kurang nyaman dan berpengaruh secara langsung atau tidak langsung pada tingkat kunjungan wisatawan. Kalau boleh janganlah "mempropagandakan kebenaran diri sendiri dengan tidak bisa menerima kebenaran orang lain," yang memang pada zaman ini sudah biasa dilakukan, demi untuk mendapatkan keuntungan material secara pribadi-pribadi dengan mencari-cari kesalahan orang lain. Seperti yang dikatakan "Propaganda can never tell the truth, truth can never be propagated. ”(Denielle \& Oliver Follmi, 2006:Th).

Pada era sekarang, dimasa modern yang telah terlewati dalam dunia post modern, ketika manusia mencari jati dirinya, adalah melalui jalan spiritual, seperti apa yang dikatakan oleh Krishnamurti; "spiritualitas itu dengan mempelajari budaya, kepercayaan atau agama dari orang lain, dan spiritualitas itulah yang menjadi spririt untuk bisa orang mengerti dan menghargai keberadaan orang lain. Pada umumnya meraka yang memiliki sifat-sifat materialime mereka akan lebih individualistis "aku adalah aku" I, me, myself. Mereka menjadi lebih rational, tetapi kalau orang memiliki sifat-sifat spiritual biasanya mereka memilki kesadaran, yang kadang-kadang dianggap irasional dimata orang yang memiliki sifat materialistis."

Dalam sejarah kehidupan manusia, manusia tidak akan pernah bisa lepas dari suatu keyakinan yang dianutnya. Keyakinan itu pada umumnya berbentuk agama yang bersifat universal (world religions), maupun kepercayaan yang bersifat lokal (native belief). Agama dan aliran kepecayaan pada saat ini banyak sekali jumlahnya dan berbeda-beda bentuknya, tetapi dari semua agama dan kepercayaan yang ada tersebut pada dasarnya mempunyai satu keyakinan yang sangat kuat, yaitu tertuju kepada keberadaan Tuhan Yang Maha Esa. Keyakinan itu menjadi pegangan hidup seseorang maupun bersama-sama dalam kelompok masyarakat untuk menjalankan dan mengatur roda kehidupan sosial mereka. Ajaran agama ataupun kepercayaan yang dianut tersebut akan memberikan pencerahan, tuntunan hidup yang pada akhirnya akan memperkuat kepercayaan Sradha dan etika Susila dari masyarakat secara holistik.

Biasanya agama dan kepercayaan yang dianut oleh kelompok-kelompok masyarakat akan sangat berpengaruh terhadap sistem sosial, stuktur sosial, etika sosial, kesenian, arsitektur, sastra dan lain sebagainya. Budaya yang berkembang dalam kehidupan masyarakat akan mewarnai kehidupan beragama, seperti bagaimana filsafat atau teologi maupun ajaran agama itu akan direalisasikan dalam kehidupan nyata dan tidak nyata (sekala nis kala). Adalah dalam rangka untuk mencapai tujuan hidup di alam ini dan tujuan akhir hidup manusia (Jagadhita dan Mokshartham) dari masyarakat tersebut. Menurut Gandhi mustahillah bagi manusia untuk menjadi sadar dan bisa mendapatkan atau mengalami kebenaran yang mutlak, selama manusia masih dipenjara didalam selubung (badan) yang fana ini. Manusia hanya dapat membayangkan dalam angan-angan, karena kelengkapan badan yang fana sulit untuk dapat mencapai atau memiliki kebenaran yang abadi. Itulah sebabnya bahwa manusia akhirnya terpaksa dan harus berpegangan pada Kepercayaan, karena akal manusia tidak mencukupi (D.S. Sarma, 1951: 20).

Dalam bukunya Made Titib (2006) menggambarkan Teologi adalah apa yang disebut Brahmawidya dalam masyarakat Hindu, seperti yang dinyatakan oleh Mahadevan (1984:300) bahwa; teologi sebagai Brahmawidya yakni; the Knowledge of Brahman. Sedangkan Apte dalam Sanskrit English Dictionary (1987:466) menerjemahkan kata teologi dengan istilah IswaraBrahmajnanam, Paraarthavidya, Adhyatmajnanam yang leksikal berarti pengetahuan tentang ketuhanan. Brahmawidya adalah pengetahuan tertinggi tentang ketuhanan dan pengetahuan spiritual, yang berarti pengetahuan tentang Tuhan Yang maha Esa mencakup semua manifestasiNya, ciptaan-Nya dan segala sesuatu yang berkaitan dengan-Nya. Istilah teologi didalam The New Oxford Ilustrated Dictionary (1978:1736) dinyatakan sebagai science of religion, study of God or gods, esp of attributes and relations with man etc, yang berarti ilmu yang mempelajari Agama, mempelajari tentang Tuhan Yang maha Esa termasuk para Dewa-Dewa beserta simbul/atributNya yang berhubungan dengan manusia dan sebagainya.

Disamping Teologi ada juga istilah Tealogi. Kata tealogi berasal dari bahasa latin Thea berarti suatu yang bersifat feminim seperti Dewi atau goddess adalah dalam rangka dekontruksi konsep Yang Ilahi menurut matriarchat. Teologi menggali dan mengembangkan konsep dewi dari peradaban barat dan timur. Teologi akan memunculkan konsep dewi yang terkubur dalam lautan pasir peradaban agama yang berpihak pada laki-laki (Andian 2001:52). Di dunia Barat inilah yang 
menjadi masalah terjadi hegomoni kaum laki-laki dalam tatanan keagamaan mereka, sehingga terjadilah perlawanan, sampai-sampai mereka mencari jati dirinya dan asal mula mereka, dengan berperilaku seperti manusia dalam abad pertengahan Medieval Period.

Berdasarkan pernyataan Andian diatas memang ada benarnya, bila dikaji dari perspektif Agama Hindu sesuai dengan konsep-konsep yang ada diantaranya; konsep Sivaisme dengan jelas menjabarkan bahwa kekuatan Siwa itu sendiri disebut dengan Shakti, dan Shakti itu ada pada Parwati yaitu istri Siva sendiri. Begitu juga sesuai dengan konsep danpengaruh ajaran Vaisnava, dikatakan kekuatan dari Visnu itu sendiri ada pada Maya-Nya yaitu Dewi Laksmi.

Peradaban Nusantara dikatakan sangat tua dan merupakan tempat pusat peradaban manusia di dunia pada zaman Atlantis, yang pada awalnya bangsa Barat mengklaim bahwa merekalah menjadi pusat peradaban manusia dibumi ini. Tetapi menurut thesisnya dari Arysio Santos, yang berjudul The Lost Atlantis Finally Found, dia membalikan fakta tersebut bahwa Timurlah yang menjadi pusat peradaban manusia di zaman dulu. Dari hasil penelitian secara interdisipliner selama 30 tahun, sebuah penelitian yang sangat panjang dan melelahkan sekali. Seorang geologi dan fisikiawan nuklir dari Brazil, dalam penemuannya yang sangat fantantis, seperti apa yang dijabarkan oleh Plato tentang Atlantis adalah sebuah "Benua yang Hilang." Plato menegaskan bahwa keberadaan benua Atlantis yang tenggelam akibat tsunami yang sangat besar, yang luasnya mencakup Libia (Afrika Utara) dan Asia Kecil yang digabung, benar-benar berada di wilayah Indonesia. Pulau-pulau di Indonesia yang sangat banyak jumlahnya, sebenarnya merupakan puncak-puncak gunung dan daratan tinggi dari benua yang tenggelam tersebut. Dataran rendahnya tenggelam ketika permulaan air laut naik pada akhir Zaman Es Pleistosen, yaitu sekitar tahun 11.600 yang lalu. Benua-pulau yang tenggelam inilah yang diperkirakan memiliki makna secara arfiah dari kata "nesos" yang dijabarkan Plato dalam dua dialognya, yaitu; Temaeus dan Critias. Benua yang hilang ini ada di daerah tropis yang sangat subur pada zaman es yaitu daerah di katulistiwa. Plato juga berbicara tentang keindahan kuil-kuil yang tidak tertandingi keindahannya dan kekayaannya, yang tercipta dari emas, perak serta timbunan dari batu permata dan logam berharga, dan semua ini tidak pernah dimilki oleh bangsa lain manapun yang ada di dunia.

Jika direnungi keadaan ini lebih saksama, mudah bagi orang untuk menyadari bahwa sebagian besar kekayaan ini adalah khas India Timur, khususnya yang ada di Indonesia. Sebenarnya dari penelitian tersebut bisa saja benua yang tenggelam ini dan muncul menjadi 'Dunia Baru" (Mundus Novus). Kata "Pulau" versi Plato, mereka percaya bahwa kata "pulau" (nesos) dalam bahasa Yunani yang digunakan Plato sebenarnya menunjukan kepada pulau-pulau yang ada di Indonesia. Kata ini juga mengandung makna "tanah yang tenggelam" dan jelas dapat disamakan dengan kata "dwipa" yang digunakan oleh orang-orang Hindu, yang dalam bahasa Sanskerta adalah merupakan daratan-daratan bagaikan surga yang sekarang tenggelam yang sama seperti kata Atlantis. "Sepanjang waktu, semua bangsa meyakini keberadaan surga primodial tempat manusia berasal dan mengembangkan peradaban untuk pertama kalinya.

Kisah yang benar dan nyata ini diceriterakan dalam Injil dan kitab-kitab suci Hindu seperti Reg Veda, Purana, Ramayana dan lainnya.” (Arysio Santos, 2010:70). Didaerah inilah lahirnya peradaban dan ilmu pengetahuan masa Atlantis tersebut dan berkembang ke seluruh penjuru dunia setelah zaman es berakhir dan benua ini dengan segala kekayaannya, keindahannya dan tenggelam akibat kejadiaan alam. Benua yang hilang adalah merupakan pusat pengetahuan, dan peradaban pada zamannya, rempah-rempah, kayu cendana adalah sarana ritual bangsa itu. Bali berada diantara daerah benua yang tenggelam ini, kalau disimak menurut penjelasan buku ini, mewarisi sisa peradaban dari zaman Atlantis tersebut. Berdasarkan hasil wawancara penulis dengan seorang astronomi dari Hongaria Rozalia Hummel; (28 Januari 2010) di Ubud, dia mengatakan bahwa; "banyak kata-kata dari bahasa Bali yang saya dengar persis sama dengan yang diucapkan oleh manusia di zaman peradaban Atlantis. Sepertinya banyak peninggalan yang dia jumpai di Bali mempunyai ciri khas zaman tersebut".

Lebih jauh dia berkata : "Bali memiliki hubungan yang sangat dekat dengan bintang Kartika menjadikan Bali pada saat ini kedatangan banyak orang dari luar. Bahkan Bali saat ini diserbu oleh orang-orang spiritual dari seluruh penjuru dunia, di Bali mereka dengan khusuk dapat melakukan Yoga dan meditasi serta untuk meningkatkan spiritualitas mereka. Serta wisatawan dapat menggali khasanah budaya local yang mempunyai nilai social religius dan spiritualitas yang tinggi. Juga karena kedekatan Bali dengan bintang Kartika tersebut Bali sangat tepat dikembangkan sebagai daerah pertanian. Cara orang Bali bercocok tanam sangat mirip dengan cara yang dilakukan oleh orang di zaman peradaban Atlantis." Sehingga seorang petani Bali kalau melakukan kegiatan bercocok tanam, maupun melakukan pelayaran, para petani atau nelayan selalu melihat bintang Kartika sebagai petunjuk "tetenger" memilih hari atau waktu yang baik untuk melakukan kegiatan tersebut. 
Bali sepertinya sudah memiliki kebudayaan yang sangat tua dengan segala local geniusnya (native belief), mengalami perpaduan dengan world religion, asfek Siva Sidhanta yang berkembang di Jawa sampai ke Bali menjadi warisan yang tiada nilainya. Di Bali agama Hindu adalah nafas dari kehidupan social masyarakat Bali yang diemban oleh Desa Pakraman yang ada diseluruh Bali, segala ajaran-ajaran suci Hindu masih secara utuh seperti Veda, Upanishad, Sarassamuscaya, Purana, Dharmasastra menjadi inspirasi masyarakat Bali unuk berkreasi. Sehingga Bali dengan segala kreatifitas sosial dan religiusnya menciptakan keindahan alamnya, arsitekturnya, keramah tamahan masyarakatnya, suasana yang penuh dengan nuansa spiritualitas inner beauty sangat menarik wisatawan dari penjuru dunia. Sehingga seperti yang telah berkembang di Desa Ubud dalam menerima dan melayani para tamu "atithi" dari segala penjuru dunia sudah memberikan pencitraan yang sangat baik dan unik dalam penerimaan dan pelayanannya. Penuh dengan senyum, ramah, terbuka, sopan, alami penampilannya, senang membantu dan tidak banyak bertingkah serta penuh dengan rasa kekeluargaan, sangat sesuai dari penjabaran ajaran-ajaran suci agama Hindu. Pelayanan yang baik tanpa mengharap atau pamerih, akan menjadikan wisatawan senang datang bahkan menetap di Ubud. Ada beberapa sumber teologi dari Pariwisata menurut ajaran Agama Dalam Sastra salah satunya Manawa Dharma Sastra.

\section{Menawa Dharma Sastra}

Ajaran moralitas yang terkandung dalam Manawa Dharma Sastra ini mengingatkan kita untuk senantiasa memperhatikan orang lain dan tidak berpuas diri. Walaupun demikian, di dalam athiti yanya, ada semacam prioritas dalam pelayanannya.

Tetapi, orang bodoh yang makan terlebih dahulu tanpa memberi kepada orang-orang demikian, sementara ia makan dengan lahapnya, ia tidak tahu bahwa setelah matinya nanti ia sendiri akan di telan oleh anjing-anjing dan burung-burung bangkai (MDS.III:115)

Orang-orang yang dapat didahulukan dalam hal menemani jamuan makan yaitu wanita yang baru menikah, bayi, orang sakit dan orang hamil. "orang yang prilakunya begini, tidak mengindahkan para Dewa, orang tua, tamu, anak-anak yang lebih dahulu harusnya makan di rumahnya, orang yang demikian raksasa namanya (SS.225)

Kedua ayat di atas bermakna bahwa sebelum kita menikmati makanan terlebih dahulu dalam sebuah perjamuan. Sivananda dalam bukunya "All About Hinduisme" mengatakan bahwa di India ada tradisi perjamuan makan malam bagi ratusan orang, karena bagi mereka memberi makan merupakan pemujaan kepada Narayana. Dan seorang Hindu percaya bahwa bila ia memberi makan kepada seorang pendeta, berarti ia sedang memberi makan seluruh dunia.

Dalam Manawa Dharma Sastra (III : 118) menguaraikan bahwa bagi mereka yang menyiapkan makanan hanya untuk dirinya sendiri, sebenarnya makan dosa, kareana sudah ditetapkan bahwa makanan yang tinggal setelah selesai uapacara adalah menjadi makanan orangoarang bijaksana, dan tidak boleh sendiri saja menikmatai sesuatau yang menyenangkan, seperti menecapa makanana yang least dan segar, sudah sepatutnyalah kita menyanjakan makan sebelum kita makan sehingga setelah kita menikmati makanan tersebut menjadi rahmat Tuhan. Krisna bersabda bahwa " yang baik adalah makan-makanan setelah uapacara yajna, mereka akan terlepas dari segala macam dosa. Tetapi menyediakan makanan lezat hanya bagi dirinya sendiri, mereka itu sesungguhnya makan dosa. Mereka yang makan dari sisa persembahan akan mencapai Brahma yang kekal abadi, dan dunia ini bukan bagi mereka yang tidak berbakti”.

"Ekamratram tu niwasannatithir brahmanah smrtah,

Anityam hi stitho yasmat Tasmat Atithir uchyate.” (MDS, III:102)

Yajnya merupakan penyangga kehidupan agar tetap tegak dan kokoh untuk mencapai Sanatana Dharma, yajna merupakan jalan kehidupan (way of life) dan jalan kesucian (way of cleanliness). Dengan melaksanakan yajnya manusia dapat menyucikan dirinya dan dengan yajnya kelak manusia menyadari bahwa dirinya pada dasarnya adalah suci (Aham brahma asmi). Aktifitas dari yajnya merupakan sebuah totalitas kesemestaan. Parajapati menciptakan manusia (prajah) bersama bhakti persembahan (sahayajnah). Athiti yajnya pada hakekatnya adalah sebuah persembahan dan pelayanan, dimana semuanya merupakan pemujaan, sehingga moralitas dalam setiap baktaNya akan menuju kepada kebersamaan dan keharmonisan. Moralitas (susila) adalah ilmu tentang prilaku, moralitas merupakan pelajaran dari apa yang benar atau baik didalam berprilaku. Moralitas menunjukkan jalan bagi manusia agar memandang sama terhadap ciptaan Tuhan. Moralitas mengandung prinsip-prinsip secara sistematis bagaimana seseorang harus bertindak (sadacara). Pelaksanaan moralitas akan membantu kita untuk hidup dalam keselarasan dengan tetangga, sahabat, anggota keluarga sendiri, dan sesama manusia.

Dalam kehidupan, kebersamaan dan keharmonisan akan menjamin terciptanya perdamaian (santih). Manusia adalah makhluk sosial, mahkluk yang senantiasa hidup bersama dan ingin mewujudkan keharmonisan dan keselarasan dalam kebersamaan. Dalam pergaulan yang kian 
mengglobal kita sering dituntut untuk dapat memposisikan diri. Perlakuan orang lain terhadap kita tergantung pada prilaku kita terhadap mereka.

Nilai-nilai tentang moralitas yang luhur dari Wedanta mengemukakan doktrin kesatuan dari kehidupan dan persatuan kesadaran, "Para Rsi, leluhur, Dewa, Bhuta dan para tamu (atihi) meminta persembahan dan pemberian kepada kepala rumah tangga. Oleh karena itu, ia yang tahu hukumnya harus memberikan mereka apa yang sesuai untuk masing-masing".( MDS.III:80). Demikianlah compedium Hukum Hindu memberikan petunjuk dan tuntunan moralitas kepada manusia. Lebih jauh tentang tata susila penghormatan dan pelayanan tamu (atithi) di uraikan demikian "Tetapi hendaknya ia memberikan sesuai dengan peraturan-peraturan kepada tamu yang datang dengan tiba-tiba, berupa tempat duduk, air dan juga makanan dengan lauk-pauknya sesuai dengan kemampuan. Selimut, kamar untuk istirahat, air dan penyambutan yang ramah, keempat hal ini selalu ada di rumah orang saleh". (MDS.III :99, 101).

\section{Penutup}

Konsep Pariwisata yang berbasis teologis pariwisata yang terdapat dalam Manava Dharma Sastra adalah bagaimana melayani tamu sebagai Dewa (Atithi Deva Bhavo), cara mempersembahkan makan memberikan pelayanan yang sangat tulus sehingga kemurahan hati para dewa, atau dalam pengelolaan pariwisata, tamu /wisatawan adalah dewa. Jika wisatawan merasa puas maka tamu akan memberikan pendapatan yang lebih bagi masyarakat yang melayaninya/pelaku pariwisata, maka sangat dianjurkan sekali dalam pengeloaan pariwisata di Bali dan Ubud pada khususnya agar memperlakukan tamu/wisatawan seperti dewa karena jika wisatawan merasa senang maka semakin banyak devisa yang akan diperoleh, Masyarakat Ubud agar mempertahankan Ubud sebagai tujuan pariwisata dunia, meningkatkan SDM (sumber daya manusia) dan terus mempertahankan alam, tata ruang Ubud harus dimaksimalkan, masyarakat dan pelaku pariwisata agar lebih selektif menerima wisatawan yang berkunjung ke Ubud, karena Ubud sarat mengandung nilai-nilai spiritual, sosial, etika dan memiliki seni budaya yang adi luhung, yang merupakan warisan yang perlu dipertahankan.

\section{Daftar Pustaka}

Adiswarananda, Swami, 2004. The Vedanta Way to Peace and Happiness. New York: Ramakrishna - Vivekananda Center.

Connoly, Peter, 2002. Aneka Pendekatan Studi Agama. Yogyakarta: LKis.

Donder, I Ketut, 2006. Brahmavidya: Teologi Kasih Semesta. Surabaya: Paramita.

Donder, I K., 2010. Teologi : Memasuki Gerbang Ilmu Pengetahuan Ilmiah Tuhan Paradigma Sanatana Dharma. Surabaya: Paramita.

Grayling, A.C., 2007. The Meaning of Things Applying Philosophy to Life. Great Britain: Clay Ltd.

Griffin, David Ray, 2005. Tuhan \& Agama Dalam Dunia Postmodern. Yogyakarta: Kanisius.

Griffin, David Ray, 2005. Visi-Visi Postmodern Spiritualisme dan Masyarakat. Yogyakarta: Kanisius.

Lueras, Leonard, 2004. Ubud is a Mood. Denpasar: The Bali Purnati.

Maswinara, I Wayan, 2003. Śrīmad Bhagawad Gītā. Surabaya: Paramita.

Maswinara, I Wayan, 2004. Veda Śruti RgVeda Samhita Sakala Sakha Mandala IV, V VI, VII. Surabaya: Paramita.

Menon, Ramesh, 2008. Siva The Siva purana Retold. New Delhi: Rupa a Co.

Olsen, Daniel, 2006. Tourism, Religion, Spiritual Journey. USA: Rootledge. 
Pendit, Nyoman S., 2006. Ilmu Pariwisata Sebuah Pengantar Perdana. Jakarta: PT. Pradnya Paramita.

Price, Joan, 2006. Climbing the Spiritual Ladder. USA: Lotus Press.

Pudja, G., 1975. Manawadharmasastra. Surabaya: Paramita.

Radhakrisna, S, 1989. Indian Philosophy Vol.I. New York : Oxford University Press

Sanerya Hendrawan, 2009. Spiritual Management. Jakarta: PT Mizan Pustaka.

Santos, Arysio, 2010. Atlantis The Lost Continent Finally Found. Jakarta: PT Ufuk Publishing House.

Śaranam, Śankara, 2009. God Without Religion Mempertanyakan Kebenaran yang Telah Diterima Selama Berabad-abad. Jakarta: PT Gramedia Pustaka Utama.

Sayanacarya, bhasya, 2005. Atharvaveda Samhita II. Surabaya: Paramita.

Spyker, Stephen K., 2007. Teknology \& Spiritual. USA: Sky Light Paths Publishing.

Smith, Huston, 2008. Agama-Agama Manusia. Jakarta: Yayasan Obor Indonesia.

Suada, I Nyoman, 2007. Bali dalam Perspektif Sejarah dan Tradisi dalam Relevansi dengan Era Global Menuju Keajegan Bali yang Harmonis. Denpasar.

Sudharta, Tjok Rai, 2003. Slokantara Untaian Ajaran Etika Teks, Terjemahan dan Ulasan. Surabaya: Paramita.

Suardana, 2010. Konsep Pariwisata Berbasis Teologi Pariwisata di Desa Ubud, Penelitian IHDN Denpasar : Denpasar

Titib, I Made, 2001. Pengantar Weda. Jakarta: Hanoman Sakti.

Titib, I Made, 2009. Teologi \& Simbol-Simbol dalam Agama Hindu. Surabaya: Paramita.

Truzzi, Marcello, Sociology: The Classic Statements. New York: Oxford University.

Wirawan, I Gusti Bagus, 2009. Arsitektur Tradisional Bali. Denpasar: Widya Dharma.

Yoeti, H. Oka A., 2006. Pariwisata Budaya Masalah dan Solusinya. Jakarta: PT Pradnya Paramita. 